\title{
AS MULHERES OU OS SILÊNCIOS DO HUMOR: UMA ANÁLISE DA PRESENÇA DE MULHERES NO HUMOR GRÁFICO BRASILEIRO [1968-2011]
}

\author{
WOMEN OR SILENCES OF HUMOR: AN ANALYSIS OF THE PRESENCE OF WOMEN IN BRAZILIAN GRAPHIC \\ HUMOR [1968-2011]
}

\section{RESUMO}

A história do humor gráfico brasileiro tem sido caracterizada por obras que demarcam a existência de um humor tipicamente nacional. Tal originalidade ocasiona a publicação de inúmeros livros que se apresentam como coletâneas que reunem os principais nomes do humor gráfico no Brasil. Nesses levantamentos os homens são uma maioria absoluta e quando as mulheres não são ignoradas por completo, elas são citadas em quantidade mínima. Diante deste cenário, o objetivo deste artigo é analisar cinco coletâneas publicadas entre os anos de 1968 e 2011 e avaliar, em termos quantitativos e qualitativos, as mulheres citadas. Como contraponto aos silêncios do humor gráfico brasileiro em relação às autoras mulheres, exploro ainda jornais alternativos feministas publicados na segunda metade do século XX, para demonstrar que diante de um cenário editorial negligente à produção das mulheres, elas encontraram caminhos alternativos para publicação de seu trabalho, construindo lugares de resistência, a exemplo do contexto atual em que a Internet é suporte fundamental para publicização de cartunistas, desenhistas, ilustradoras e quadrinistas brasileiras.

Palavras-chave: Mulheres. Silêncios. Humor gráfico. Resistência.

\begin{abstract}
History of Brazilian graphic humor has been characterized by works that mark the existence of a typical national humor. This originality causes the publication of a variety of books that present themselves as collections, anthologies and encyclopedias that bring together the main names of graphic humor in Brazil. In these researches men are absolute majority and when women aren't completely ignored, they are cited in minimal quantity. With this scenario, the goal of this article is to analyze five collections/anthologies/encyclopedias published between 1968 and 2011 and evaluate, in quantitative and qualitative terms, women cited. As a counterpoint to the silences of Brazilian graphic humor regarding women authors, I intend to explore feminist underground newspapers published in the second half of the XX century, to show that facing the negligent editorial landscape of women's production, they found their alternative ways to publish their work, building spaces of resistence, just as the current context that Internet is the fundamental support to advertising of Brazilian cartoonists, designers, illustrators and comic artists.
\end{abstract}

Keywords: Women. Silences. Graphic Humor. Resistence.

Cintia Lima Crescêncio

Universidade Federal do Mato Grosso do Sul (UFMS). E-mail: climahist@gmail.com 


\section{Considerações iniciais}

Em 10 de março 2016 a cartunista Aline Lemos compartilhou, via redes sociais, uma lista aberta em que enumerava quadrinistas, desenhistas, coloristas, letristas, roteiristas e outras atuantes no quadrinho brasileiro. A lista A legião de mulheres nos quadrinhos no Brasil era aberta à edição e convidava todas a incluírem seus nomes e/ou de outras. No dia 13 de maio de 2016 a lista contava com 432 nomes. Junto a eles, sites, blogs, tumblrs e redes sociais eram indicados como lugar privilegiado de publicização de humor gráfico e quadrinhos produzidos por mulheres. A lista contava com figuras bastante conhecidas do público - ao menos do público interessado pela produção assinada por mulheres - como Mariza, Ciça, Crau', Alexandra Moraes e outras. A maioria esmagadora das artistas listadas, no entanto, não mantém contratos com editoras ou é contratada por jornais de grande circulação. Em grande parte suas produções circulam por um universo independente que, hoje, tem como aliado a rápida difusão da informação via Internet. A lista, mais do que visibilizar a produção de mulheres no ramo dos quadrinhos brasileiros, incluído aí o humor gráfico, demonstra que elas criam e/ou encontram outros espaços de publicização de sua produção, uma resposta ou mesmo fuga dos mecanismos tradicionais de circulação que, no geral, pouco contribuem para a divulgação de humor gráfico produzido por mulheres no Brasil ${ }^{2}$. A revista As Periquitas, Meninas com humor e opinião, publicada em 2014, confirma esse cenário3. No editorial da revista, assinado por Crau, uma correspondência da cartunista Thais Linhares, afirma: "A internet é meu elixir de volta à vida. Antes, era impossível, e digo isso sem exagero, fazer nome nesse meio [...] com internet pode até não ganhar dinheiro, mas pelo menos se consegue distribuir seu material" (Crau [et al], 2014: 1-3). Estamos, portanto, diante de novas formas de ação que se contrapõem à exclusão das mulheres no humor gráfico no Brasil.

Tendo como foco os debates que apontam a invisibilidade do humor das mulheres ${ }^{4}$, bem como as estratégias de circulação encontradas por elas, o presente texto tem como objetivo debater o silenciamento do humor gráfico produzido por mulheres no Brasil, na segunda metade do século XX e nos primeiros anos do século $\mathrm{XXI}$, a partir do cruzamento de dois tipos específicos de documentos pensados tanto

\footnotetext{
1 Crau foi importante representante do quadrinho alternativo no Brasil dos anos 1970 e, apesar disso, não foi citada por nenhuma das coletâneas analisadas. Moacy Cirne, no livro História e crítica dos quadrinhos brasileiros, em capítulo dedicado ao quadrinho alternativo, mais especificamente as revistas Balão e $O$ Bicho, aponta como o número 7 da revista, que teve oito edições, fez uma curiosa experiência ao parodiar o programa Fantástico. Na equipe de produção estavam Fortuna, Cláudio Paiva, Coentro, Nani, Zeluco, Crau, Guidacci, Mollica e Mariza (1990: 72).

2 A lista foi incluída como anexo em minha tese de doutorado intitulada Quem ri por último, ri melhor: humor gráfico feminista (Cone Sul, 1975-1988), defendida em 2016 no Programa de Pós-Graduação em História da Universidade Federal de Santa Catarina. Depois de finalizada a tese, a lista continuou em edição. Dissertação de mestrado de Jessica Daminelli Eugênio (2017: 92) apontou, em 2017, 435 nomes na listados.
}

3 A revista é um antigo projeto da cartunista Crau da Ilha que encontrou possibilidade de publicação com a parceria de Cristina Merlo e da Editorial Kalaco.

4 Merecem menção os trabalhos de Regina Barreca, Nancy Walker, Janet Bing, Mariela Acevedo, Joanne Scheibman, Mara Burkart, Trina Robbins, Alba Tinoco da Silva, Daiany Ferreira Dantas. 
quantitativamente, com foco na identificação de quantas mulheres são citadas, bem como qualitativamente, enfatizando como elas são citadas e, caso não citadas, como são representadas.

Cinco coletâneas 5 de humor publicadas entre os anos de 1968 e 2011 são exploradas como fontes principais, material que permite uma análise bastante crítica no que se refere aos silêncios do humor - enquanto campo - em relação à produção com assinatura de mulheres ${ }^{6}$. Em um movimento de contraposição e no sentido de apontar como historicamente as mulheres buscaram outros meios de publicizar seu trabalho, a exemplo da lista A legião de mulheres nos quadrinhos no Brasil de 2016 e do trabalho da revista As Periquitas, o resultado da análise das coletâneas é articulado a três jornais alternativos feministas brasileiros7. Tais jornais, publicados entre os anos de 1975 e 1988, são explorados como fontes secundárias, para demonstrar que, diante da negativa do mercado editorial brasileiro, cartunistas, chargistas e quadrinistas mulheres encontraram outros caminhos de publicização. Se no começo do século XXI o caminho trilhado foi de amplo uso da Internet, na segunda metade do século $\mathrm{XX}$ os jornais alternativos feministas foram um importante lugar de publicização e por que não, de demonstração de resistênciå ${ }^{8}$.

Para isso o artigo foi dividido em três distintos momentos com base nas fontes e nas conclusões que elas inspiram. Primeiramente elaboro uma reflexão sobre o cenário dos quadrinhos no Brasil a partir dos anos 1960, de modo a localizar no tempo o debate sobre emergência do humor gráfico no cenário nacional. Já nesse momento elaboro uma reflexão sobre esse modelo de humor gráfico ${ }^{9}$ e o lugar das mulheres nele. Posteriormente discuto as duas coletâneas da segunda metade do século XX - Antologia do humor brasileiro (2 volumes), de 1968, e Dez em humor, de 1976 - que, no geral, trazem poucas ou nenhuma mulher. Por último analiso as três coletâneas do começo do século XXI - História do Brasil através da caricatura, de 2001; Entre sem bater! O humor na imprensa: do Barão de Itararé ao Pasquim21, de 2004; e Enciclopédia dos Quadrinhos, de 2011 -, procurando discutir os motivos pelos quais as mulheres continuam não sendo citadas por obras que procuram se afirmar como referências no ramo do humor gráfico. Inspirada em Michelle Perrot, a reflexão sobre tais fontes tem como lente o silêncio, conveniente à posição considerada secundária e subordinada das mulheres (2005: 9). O humor gráfico, como leitores e leitoras observam nas páginas seguintes, nada tem de subversivo ou

5 Neste artigo o termo coletânea inclui antologias e enciclopédias.

6 As coletâneas foram adquiridas online, em sites de livrarias e plataformas de venda de livros usados.

7 Os jornais Brasil Mulher e Nós Mulheres fazem parte do acervo do Laboratório de Estudos de Gênero e História da Universidade Federal de Santa Catarina, onde foram consultados. O jornal Mulherio está disponível para consulta online no site da Fundação Carlos Chagas.

8 Os movimentos feministas que emergiram no Brasil a partir na segunda metade do século XX tinham forte vínculo com as esquerdas e com os movimentos de mulheres, ambos opondo-se às consequências do golpe civil-militar de 1964. No período as principais discussões giravam em torno dos seguintes temas: trabalho doméstico, mercado de trabalho, sexualidade, direitos reprodutivos, saúde, violência contra mulher e etc, assuntos que mobilizaram esses jornais desde 1975, com a fundação do Brasil Mulher.

9 Refiro-me especialmente a um humor gráfico que foca no debate político - institucional - e faz uso de uma modalidade de humor que se baseia na violência e no ridículo. 
desobediente quando o assunto são as mulheres. Ele obedece no trato, objetificando corpos femininos, e se conforma na exclusão parcial ou completa das mulheres. Os dois momentos de debate sobre as coletâneas são, ainda, o momento em que aciono os jornais alternativos feministas Brasil Mulher (1975-1980), Nós Mulheres (19761978) e Mulherio (1981-1988) ${ }^{10}$ como suporte para demonstrar como eles funcionaram como um lugar de parceria e valorização de cartunistas e quadrinistas mulheres, afirmando-se como espaço de resistência histórica, cultural, política e intelectual.

\section{Breve histórico do (silêncio do) humor gráfico no Brasil}

Junior Gonçalo aponta que nos anos 1960 as histórias em quadrinhos eram um fenômeno de comunicação de massa incorporado ao cotidiano urbano brasileiro. 150 mil gibis circulavam todo o mês distribuídos pelas cinco editoras consideradas mais importantes: Ebal, RGE, O Cruzeiro, Abril e La Selva. Jerônimo, o herói do sertão e as Aventuras de O Anjo, eram produzidos no Brasil e os gibis mais vendidos da RGE (2004: 324), sucesso que levou a uma luta pela nacionalização da produção, em um esforço de valorizar o mercado nacional.

Em 1963, os leitores brasileiros que tinham o hábito de ler revistas em quadrinhos podiam se considerar privilegiados. Num dos períodos mais tensos da vida política brasileira, quando a conspiração para derrubar o presidente João Goulart caminhava a passos largos para o desfecho trágico de um golpe militar no ano seguinte, circulavam regularmente, em meados daquele ano, mais de duzentos títulos, entre publicações mensais e quinzenais, de acordo com levantamento da revista Publicidade \& Negócios. $\mathrm{O}$ volume de vendas a cada mês foi estimado em 20 milhões de exemplares - em média, cerca de 100 mil revistinhas para cada título, ou 240 milhões de exemplares por ano. Outro fenômeno editorial também já havia se estabelecido no país naquele momento: a publicação diária de tiras de quadrinhos em jornais. Duas empresas dominavam o mercado de distribuição desse formato de história e atendiam a cerca de 120 jornais de todo o Brasil: Record e a Apla (Gonçalo, 2004: 363).

O autor aponta o grande número de quadrinhos que circulavam no Brasil no período pré-golpe e destaca que o debate em torno dessa produção tinha relação direta com a questão da profissionalização, mas também com a possibilidade de

10 Brasil Mulher e Nós Mulheres são costumeiramente citados como integrantes da imprensa alternativa brasileira, uma vez que emergiram de maneira independente no cenário de combate à ditadura que vigorou entre os anos de 1964 e 1985. Mulherio teve sua emergência marcada por financiamento internacional e por uma equipe profissional de produção, em função disso, muitas vezes, ele não é citado como integrante da imprensa alternativa. Neste artigo, contudo, os três jornais são considerados imprensa alternativa feminista, uma vez que, em termos de forma e de temática, eles se assemelham. 
criação de um mercado lucrativo para as editoras. O crescimento das vendas foi acompanhado, ainda, pela emergência das tiras em jornais. O Decreto № 52.497, de 23 de setembro de 1963, visava disciplinar o mercado brasileiro e, no caso das tiras de jornais, exigia que a cada sete publicadas, três deveriam ser de artistas do Brasil, sendo que esse número deveria ser crescente, chegando a seis nacionais para quatro estrangeiras depois de seis meses de vigência da lei (Gonçalo, 2004: 365). Ziraldo e Fortuna foram exemplos de cartunistas/quadrinistas/desenhistas que lutaram pela criação de legislação que valorizasse a produção interna (Gonçalo, 2004: 365).

Junior Gonçalo destaca a insatisfação dos editores com tal medida e, no aguardo por uma decisão do Supremo Tribunal Federal sobre o decreto, aconteceu o golpe de 1964. Foi apenas em 1966 que esse cenário de valorização da produção nacional encontrou êxito (Gonçalo, 2004: 366-375), ao menos oficialmente. Essa luta era acompanhada pela criação de personagens considerados tipicamente regionais: gaúchos, cangaceiros, indígenas.

No contexto de ditadura, portanto, ampliou-se o mercado e, segundo Selma Regina Nunes de Oliveira, apesar do processo de nacionalização, os quadrinhos brasileiros tiveram inspiração e são, ainda hoje, marcados pelo formato estadunidense (Oliveira, 2007:15). São poucas as informações sobre quadrinistas mulheres integradas a esse mercado, embora os anos 1960 tenham sido palco de aumento significativo de personagens mulheres. De acordo com Oliveira tal aumento tem muito mais relação com uma variação de corpos, estéticas e etnias, do que uma conscientização feminista que poderia ser fruto do período, principalmente no contexto dos Estados Unidos (Oliveira, 2007: 125). A autora conclui que, apesar das diferentes eras vividas pelos quadrinhos, os modelos de personagens femininos são os mesmos e não cansam de se repetir: a mãe, a guerreira, a órfã, a tola, a frágil, a prostituta, a vingativa, a mística, a intuitiva, a devoradora e sedutora (Oliveira, 2007: 128). Para além de um cenário que rejeitava a produção das mulheres, há ainda um contexto de representação das mulheres aliado a modelos de feminilidade estereotipados e que exploram o binarismo. Michelle Perrot, referindo-se à história, destaca como "As mulheres são mais imaginadas do que descritas ou contadas [...]" (Perrot, 2005: 11), assertiva que pode ser adequada, sem dificuldade, para o domínio do humor gráfico e dos quadrinhos.

Articulando tal afirmação com o cenário brasileiro, Oliveira indica as personagens de Angeli como representantes dos modelos comuns que figuram nos quadrinhos estadunidenses e brasileiros (2007: 128)" ${ }^{11}$. Rê Bordosa e Mara Tara merecem menção especial uma vez que, apesar de serem citadas, muitas vezes, como símbolo da libertação feminista, em função da liberdade sexual usufruída, suas vidas são solitárias, tristes e trágicas. Rê Bordosa foi morta por seu criador em dezembro de 1987. Em filme intitulado Dossiê Rê Bordosa (2008), que cria uma investigação

11 É importante lembrar, contudo, que outras feminilidades figuravam nas tiras brasileiras. Graúna, por exemplo, foi uma personagem criada por Henfil nos anos 1970 e oscilava momentos de submissão e rebeldia ao contracenar com o personagem Zeferino. Em entrevista a Tárik de Souza, Henfil afirmou que criou Zeferino para chamar os homens a enfrentar à ditadura e ao final quem se destacou foi Graúna, que conquistou as mulheres (Henfil, 2014: 47). 
para apurar a morte da personagem, Angeli afirmou: "Eu não gosto de mulher igual a Rê Bordosa. Me incomoda. Tenho amigas assim, mas, me incomoda"12.

Rê Bordosa e Mara Tara foram fruto de um período em que os movimentos feministas brasileiros, na virada dos anos 1970 e 1980, avançaram em direção a discussões sobre liberdade sexual, corpo e prazer. As personagens, contudo, foram construídas como representação limite. Rê Bordosa, por exemplo, acorda em camas estranhas com homens desconhecidos. Diante de uma possível gravidez, atribui a paternidade ao conhaque, pois é incapaz de se recordar dos parceiros sexuais. Enquanto O Pasquim criava mulheres objetos, burras e feias, entre os anos 196o e 1970, personagens como as de Angeli emergiam com um discurso aparentemente "novo", mas que, na prática, pouco contribuia para romper com expectativas tradicionais de gênero.

De acordo com Oliveira:

A teoria feminista auxiliou-nos na investigação dos modelos femininos construídos pelos roteiristas e pelos desenhistas de hqs - representações duplas como virgem/vagabunda, esposa dedicada/esposa fútil, a feia inteligente/a bonita tola, a morena boa/a loura má, a mocinha/vilã e muitas outras construções (Oliveira, 2007: 29).

É essa abordagem que, hoje, permite-nos desconfiar da ampliação do número de personagens mulheres nos quadrinhos e seguir um caminho que produz a crítica sobre a constituição de tais personagens. O Pasquim é um excelente exemplo disso. Jornal que reuniu boa parte dos principais quadrinistas brasileiros entre os anos 1960 e 1980, fielmente citados em todas as antologias sobre humor, ele também foi um dos principais críticos do feminismo, apesar de defender rigorosamente a liberdade sexual das mulheres, e não porque defendia que as mulheres eram donas de seus próprios corpos. Millôr, Ziraldo e Jaguar são figuras que se destacavam na criação de mulheres nuas e burras. Se inteligentes, eram obrigatoriamente feias e/ou feministas.

O jornal, que é importante marco da história do humor no Brasil foi, portanto, assumidamente misógino. Fonseca afirma, em tom condescendente, que o jornal tornou-se uma "[...] válvula de escape para uma época de severa censura de opinião" (Fonseca, 1999: 206) ${ }^{13}$. Pois a válvula sustentava-se com discurso que atacava minorias políticas, especialmente as mulheres. Apesar disso, em termos gerais, há muito cuidado em criticar o jornal, sempre sob argumento de que ele desempenhava um papel fundamental em tempos sombrios da história brasileira. De fato, o contexto de circulação do $O$ Pasquim não era nada favorável, mas favorável também não era

12 Disponível em: https://www.youtube.com/watch?v=RmMIx8kmy7w Acesso em 10 de agosto de 2018.

13 A obra Caricatura: a imagem gráfica do humor, publicada em 1999, de autoria de Joaquim da Fonseca, chegou a ser considerada como fonte para a produção deste texto, contudo, em função de sua forma de organização, a obra foi elencada como material de referência - passível de crítica - e não como fonte de análise quantitativa e qualitativa. O livro é uma contribuição para o debate sobre caricatura em termos de linguagem, expressão e história, embora em todos os capítulos traga breves listas de nomes importantes do humor gráfico. 
o tratamento que ele cedia às mulheres e às feministas do período. Mesmo com colaboradoras como Ciça e Mariza, figuras reconhecidas no ramo do humor gráfico e até mesmo citadas por algumas das coletâneas aqui analisadas, o jornal não perdia a oportunidade de reduzir mulheres a bundas e a ridicularizar feministas como Betty Friedan. Até mesmo Henfil, simpatizante do feminismo, quando publicava no jornal, mostrava um lado nada generoso ao se referir às mudanças promovidas pelo movimento na feminilidade das mulheres (Soihet, 2005: 596). Nas coletâneas aqui analisadas as mulheres são escassas, mas - nas imagens - a redução das mulheres a seios e bundas é farta.

Sandra Maturana Moretti afirma que "O machismo é realmente forte nos quadrinhos”, o que fica evidente na construção de figuras de mulheres gostosas ou gordinhas cômicas. Esse cenário, no entanto, vem sendo afetado pelo feminismo das autoras atuais que questionam antigos estereótipos femininos (Crau [et al], 2014: 40). O mesmo vale para as mulheres que publicavam nos jornais feministas. A configuração de lugares de resistência para divulgação de ideias contra-hegemônicas afirma-se, nesse sentido, como ação fundamental para cartunistas e quadrinistas mulheres do século XX e XXI.

As mulheres precisam estar nuas, serem fúteis, bêbadas, feias ou bonitas para serem protagonistas de tiras e charges? Sendo a resposta sim ou não, é preciso perguntar do que elas precisariam para serem autoras, ao invés de se contentarem com uma representação que, segundo Ricky Goodwin, lhes seria benéfica. Goodwin insiste em acalmar leitores e leitoras ao dizer que mesmo não produzindo humor gráfico - de acordo com levantamento feito pelo jornalista -, elas eram representadas por ele e, aparentemente, isso seria o que importa (2011: 552).

Considerar os silêncios do humor no que se refere à autoria de mulheres é essencial, não apenas porque precisamos apontar a incompletude de enciclopédias, antologias e histórias que são escritas com a parcial ou completa negação da participação das mulheres, mas também porque esses silêncios colaboram na construção de um humor, seja gráfico, seja escrito, seja falado, que nega o considerado "feminino", sendo produzido, portanto, como masculino.

Quando autores de coleções, que incluem artistas do humor gráfico, como Goida e Kleinert, em um dos poucos verbetes sobre mulheres que encontramos na Enciclopédia dos Quadrinhos, afirmam que "Não é muito fácil encontrar mulheres quadrinistas [...] (Goida e Kleinert, 2011: 72), eles reforçam tais silêncios e, por mais esforço que tenham feito na localização de mulheres para sua enciclopédia, constroem a ideia de que não há mulheres em tal campo e por isso elas não são fáceis de serem "encontradas". Nega-se, portanto, que o silêncio das mulheres nesse campo é fruto de uma operação histórica, política e cultural. Essa operação é visível em duas frentes. Primeiro, quando as rejeita na origem, ao não permitir que elas desenvolvam e/ou tenham habilidades reconhecidas no campo da arte - dominada pelos homens. Segundo, ao ignorá-las quando, superados os obstáculos iniciais traços muito femininos, humor muito doméstico, escrita muito focada no privado -, produz coletâneas sobre quadrinhos, humor gráfico e humor na imprensa em que 
as mulheres citadas são nulas ou quase nulas. O silêncio, nesse sentido, não é das mulheres, o silêncio é do humor ${ }^{14}$ enquanto campo de pesquisa, de disputa (Possenti, 2014: 171).

Alba Valéria Tinoco Alves Silva, em pesquisa sobre humor escrito por mulheres, insinua um processo de invisibilização constante e repetido que inclui também o humor gráfico. Ao observar que muitos escritores produzem humor gráfico - e vice-versa - como Ziraldo, Henfil, Millôr e Luiz Fernando Veríssimo, a autora ampliou sua reflexão para o humor gráfico, concluindo que na imagem gráfica do humor, as mulheres também são omitidas (Silva, 2015: 92) ${ }^{15}$. Trata-se de um efeito dominó: recusam-se ou desqualificam-se as mulheres artistas, logo recusamse ou desqualificam-se as mulheres escritoras, logo recusam-se ou desqualificamse as mulheres ilustradoras e assim por diante. No caso do humor essa recusa e desqualificação é potencializada, já que há um medo histórico do humor e do riso das mulheres ${ }^{16}$.

Para refletir sobre os silêncios do humor, e não das mulheres, nas coletâneas brasileiras, as fontes foram divididas em dois grupos distintos, tendo como base um recorte temporal, já que a obra mais antiga é de 1968 e a mais recente de 2011 . Duas obras compõem o primeiro grupo de livros, publicados, respectivamente, nos anos 1968 e 1976 (2 volumes). Três obras compõem o segundo grupo, publicadas, respectivamente em 2001, 2004 e 2011.

O recorte temporal específico é a virada do século, motivado pela emergência e popularização da Internet no Brasil e, consequentemente, da aceleração da circulação da informação. Contrariando expectativas, as coletâneas do primeiro grupo não apresentam um número menor de cartunistas mulheres, se respeitadas as proporções de números de páginas e amplitude da pesquisa, o que significa que, em termos editoriais, o cenário para as mulheres cartunistas, quadrinistas, ilustradoras, continua pouco favorável no século XXI. Pensando no amplo uso que atualmente se faz da Internet para divulgação de trabalhos que envolvem quadrinhos e humor gráfico, uma enciclopédia publicada em 2011, em teoria, poderia ter uma diversidade de gênero muito significativa, o que não aconteceu. Mesmo diante de um momento histórico novo, a abordagem é antiga. Crau, no edital de As Periquitas, aponta que na década de 1980 uma mesa no Salão de Humor de Piracicaba reuniu 100 cartunistas e ela se viu como a única mulher. Nos anos 1990,

14 Tal referência ao silêncio do humor faz menção especificamente ao campo de pesquisa que tem mantido as mulheres à sombra.

15 Alba Valéria Tinoco Alves Silva fez um levantamento quantitativo de citações de autoras mulheres em 12 coletâneas e obras de referência que versam sobre humor gráfico, humor e literatura, são elas: História da Caricatura no Brasil (2012), de Luciano Magno - nenhuma mulher; Imprensa, humor e caricatura (2011), organizado por Isabel Lustosa - nenhuma mulher; Entre sem bater (2004), de Luís Pimentel - uma mulher; Piracicaba, 30 anos de humor (2002), de Leandro Konder - 189 humoristas, sete mulheres; Barão de Itararé: o humorista da democracia - 15 humoristas, nenhuma mulher; Raízes do riso (2002), de Elias Thomé Saliba, 51 humoristas, nenhuma mulher; Os 100 melhores contos de humor da literatura universal (2001), organizado por Flávio Moreira da Costa - 21 homens, uma mulher; Revista Bundas, ano 1, número 1 (1999) - nenhuma mulher; Antologia Brasileira de humor (1976) - duas mulheres; O melhor do Pasquim 1969-1970, nenhuma mulher; Antologia de Humorismo e Sátira (1969), organizado por R. Magalhães Jr, 132 homens e quatro mulheres (2015: 91-92).

16 Regina Barreca aponta que o medo do humor das mulheres está vinculado ao medo do poder das mulheres (1991: 130). 
quando o projeto da revista deu os primeiros passos, um levantamento breve reuniu 40 nomes de mulheres (Crau [et al], 2014: 2). Não se trata, portanto, de um desinteresse das mulheres pelo campo, mas sim de uma operação sistemática de exclusão de seus nomes e trabalhos das publicações.

\section{Um passado que não passa}

A obra Dez em humor, publicada em 1968, é resultado de trabalho coletivo tendo sido idealizada por Fortuna, contando com a colaboração de Belmiro Pires, Leon Eliachar, Ziraldo, Jaguar, Claudius, Mario Paulo, Francisco Ventura, Fernando Castro Ferro e Carlinhos, com prefácio de José Carlos Oliveira, nome que acompanha, na capa, os 10 produtores de riso que são alvo da obra. Não é necessário folhear seu interior, portanto, para concluir que não há mulheres nessa coletânea, trata-se de um "clube do bolinha"17 assumido e orgulhoso.

Publicado durante a ditadura, e também na era de ouro do humor gráfico no Brasil, o livro é uma ode a dez nomes do humor brasileiro, cada um tem seu capítulo que conta com uma breve apresentação. Millôr Fernandes, Leon Eliachar, Stanislaw Ponte Preta, Fortuna, Ziraldo, Jaguar, Claudius, Zélio, Henfil e Vagn, são apresentados com alguns excertos de suas produções, poucos textos, o foco é em charges, tiras, caricaturas e quadrinhos. José Carlos Oliveira, em seu prefácio, aponta o livro como "uma verdadeira bomba de fabricação caseira" (Jaguar [et al], 1968: 5).

Como esperado, seu conteúdo traz muitas representações de mulheres, poucas estão vestidas. O capítulo de Jaguar é praticamente uma Playboy feita a nanquim. Na primeira charge um homem, deitado em um divã, é observado pelo seu psicanalista. Um balão de fala repleto de corpos de mulheres nuas que ocupa quase integralmente a página, dá o tom (Jaguar [et al], 1968: 89). É como se Jaguar justificasse as escolhas da maioria dos quadrinistas/cartunistas/humoristas do país. No capítulo de Claudius a caravana de Cabral se aproxima do que hoje chamamos Brasil e um de seus navegantes grita, ao avistar quatro mulheres nuas na beira de uma praia: "Pessoal! Chegamos às índias" (Jaguar [et al], 1968: 105). Na charge, as mulheres são como a terra a ser colonizada. No capítulo de Fortuna uma mulher nua recebe a ordem: "Vista-se". 11 cenas depois, ela recebe nova ordem: "Está na hora do seu número de strip-tease" (Jaguar [et al], 1968: 59). Afirmo, sem medo: se retirada a possibilidade de representação do corpo das mulheres no livro, sobrariam páginas apenas para um folheto. A redução das mulheres a um corpo é muito significativo do que se espera delas.

As roupas do homem, como seu corpo, devem indicar sua transcendência e não deter o olhar; para êle, nem a elegância nem a beleza consistem em se constituir em objeto; por isso não considera, normalmente, sua aparência como reflexo de seu ser. Ao contrário, a própria sociedade pede à mulher que se faça objeto

17 Referência ao clube composto exclusivamente por meninos cujo lema era "menina não entra" da história em quadrinhos protagonizada por Luluzinha, personagem criada em 1935 por Marjorie Henderson Buell. 
erótico. O objetivo das modas, às quais está escravizada, não é revelá-la como um indivíduo autônomo, mas ao contrário privá-la de sua transcendência para oferecê-la como uma presa aos desejos masculinos (Beauvoir, 2009: 296).

Simone de Beauvoir, ao identificar a existência de uma mulher narcisista, resultado dos discursos sobre o que é ser mulher, aponta que a mulher é feita para deter o olhar e se ver como objeto, se abandona e se encontra no espelho, no reflexo da imanência, já o homem transcende, é ação, e não se reconhece na imobilidade da imagem, pois ele não é feito objeto (2009: 614). Nas charges de Dez em humor a mulher existe como corpo e objeto, não como sujeito. A obra, além de não incluir nomes de mulheres como produtoras de humor, ainda elaborou uma seleção de imagens que reforçam estereótipos e expectativas tradicionais de gênero, fazendo uso de um humor baseado no ridículo e na violência simbólica.

O livro Antologia brasileira de humor, publicado em dois volumes em 1976, teve organização de um conselho editorial composto por Edgar Vasques, Guaraci Fraga, Ivan Gomes Pinheiro Machado, Luis Fernando Veríssimo, Paulo de Almeida Lima e Renato Canini. Assim como a obra anterior, o livro não tem mulheres na equipe editorial. Este, contudo, ao propor um levantamento de A a Z, distribuído em um total de 507 páginas, apresenta nomes de mulheres. No volume 1, com 253 páginas e 42 nomes, uma é mulher, Ciça. No volume 2, com 254 páginas e também com 42 nomes, uma é mulher, Mariza. Melhor do que nada, diria o otimista. No levantamento de 84 nomes, dois são de mulheres, um por livro. Parece que o conselho editorial do livro Antologia brasileira de humor é de uma mulher só! Elas não foram ignoradas completamente, mas causa espanto a timidez com que foram citadas. Tanto Ciça quanto Mariza foram colaboradoras do O Pasquim e publicavam em grandes jornais. Mariza não publicava em periódicos feministas como Ciça, mas fez uma breve aparição no Nós Mulheres, em 1977.

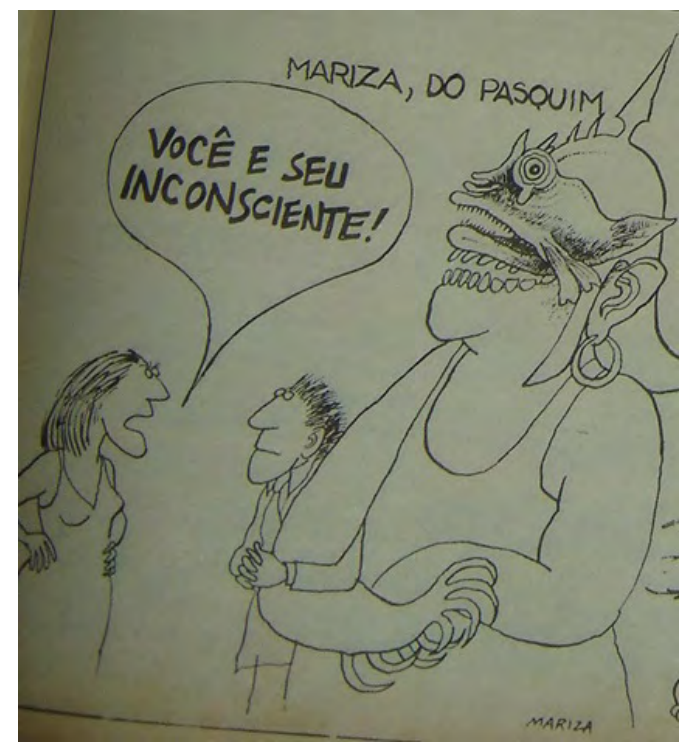

Figura 1 - MARIZA. (1977). Nós Mulheres. São Paulo. Número 4, Março-Abril, p. 9. 
Na apresentação da antologia, assinada pelo conselho editorial, os organizadores apresentam o humor brasileiro como o filho pródigo de uma grande família, cuja paternidade seria de cinco homens: Barão de Itararé, Sérgio Porto, Millôr Fernandes, Ziraldo e Jaguar. A mãe? "A mãe que nos pariu é a atual conjuntura” (Adail [et al]., 1976: 6). Vale reforçar que em 1976 o país ainda vivia o contexto de ditadura, a imprensa sofria forte repressão e vigilância e são poucas as notícias de ditadores que riam das tiradas do O Pasquim, lar de muitos desses nomes. Ser a "mãe" desses cinco nobres filhos, nesse sentido, não é muito lisonjeiro para a mãe, embora devesse ser motivo de orgulho em função de prole tão talentosa.

Nos verbetes dedicados a Ciça e Mariza o tom é objetivo, assim como dos outros 82 nomes. É apresentado data e local de nascimento e um breve resumo da carreira, com destaque para alguma história ou personagem mais famoso. Elas não são citadas porque são esposas ou filhas de alguém, como acontece em outras obras. São citadas porque fazem humor gráfico. Na seção de pioneiras da revista As Periquitas, Ciça é apontada como a primeira mulher a desenhar uma tira diária brasileira (Crau [et al], 2014: 69).

No verbete de 1976 Ciça é lembrada por sua série O Pato, que fez muito sucesso. Na seleção de suas tiras aparecem ainda suas histórias do formigueiro e das galinhas. Era o recurso da cartunista, seus protagonistas eram animais. Sua personagem Bia Sabiá, figura frequente em jornais alternativos feministas a partir de 1976, contudo, não é citada no verbete nem compõe a coletânea de tiras. A personagem, representada por um pássaro, protagoniza as agruras da vida de esposa, mãe, dona de casa e trabalhadora. Bia Sabiá politiza o espaço privado denunciando a dupla jornada, o tratamento dado às mulheres no mercado de trabalho e o lado ignorado da maternidade. Tal faceta da obra de Ciça, contudo, não é destacado. A mesma Bia Sabiá foi protagonista de cinco tiras publicadas no jornal Nós Mulheres. Em oito edições do jornal, publicadas entre os anos de 1976 e 1978, foram publicadas um total de 22 charges/tiras e quase $25 \%$ delas eram da personagem que não foi citada pela Antologia brasileira de humor. A primeira aparição da personagem, no jornal Nós Mulheres, foi em junho de 1976, mesmo ano de publicação do livro. No jornal Brasil Mulher, Ciça publicou apenas uma vez, também uma tira protagonizada por Bia Sabiá, em 1978. 


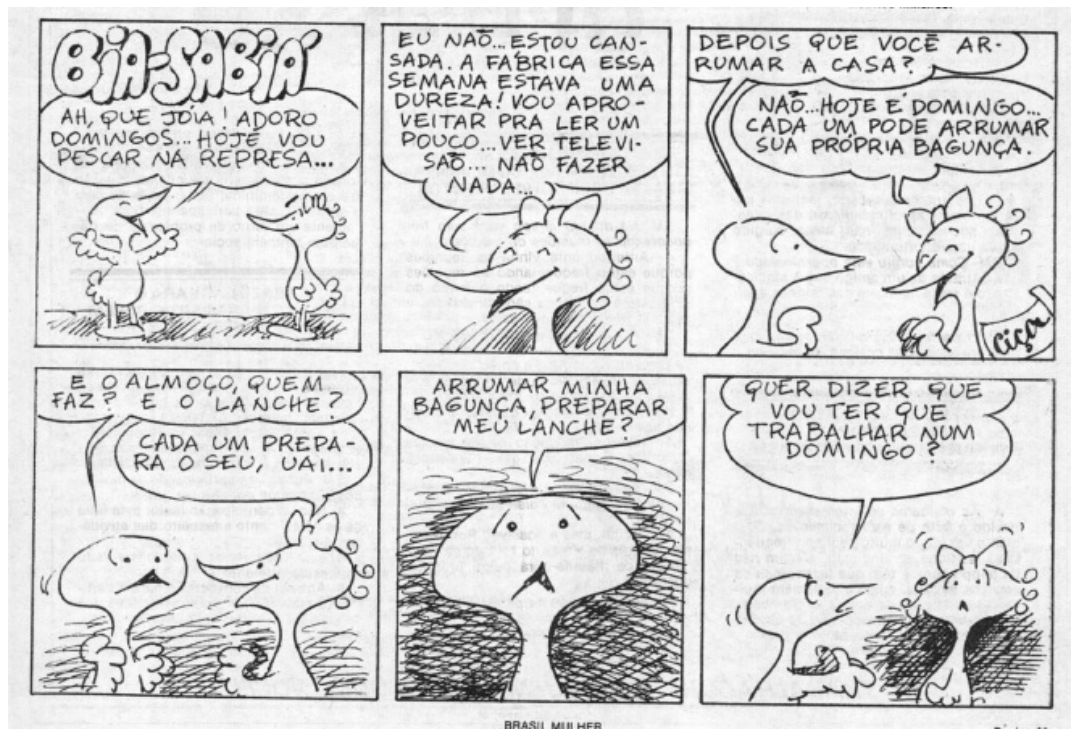

Figura 2 - CIÇA. (1978). Brasil Mulher. São Paulo. Número 11, março, p. 11.

É viável fazer uma análise que temporalize as aparições de Bia Sabiá. A primeira tira da personagem foi localizada em uma publicação de 1976, mas certamente é possível colocar em debate o desinteresse pela divulgação de um humor que, nos Estados Unidos, ficou conhecido como humor doméstico. Tal crítica é muito comum ao trabalho artístico de mulheres, elas seriam muito "específicas" e "pessoais" em seus temas. Tendo o humor o desejo pelo que é público, é interessante observar como o privado, no caso da elaboração de coletâneas, antologias e enciclopédias, pode ser facilmente rejeitado, seja pela própria autora, no caso de Ciça - ao imaginar que certa seleção de tiras não é do interesse dos organizadores -, seja pelos organizadores da obra em si. Enquanto Eleni Varikas, a partir de uma crítica feminista, aponta o privado como lugar de contestação dos costumes, ou seja, o lugar do político (1996: 63), o sistema no qual vivemos celebra o privado como o lugar do "feminino" e o casamento como ganha-pão e única forma das mulheres justificarem socialmente sua existência (Beauvoir, 2009: 408). Dito de outro modo, as coletâneas exploradas neste texto primam pela valorização de um humor que nega a domesticidade, logo, mesmo quando Ciça é citada, sua produção é destacada a partir de um outro viés que não os desafios cotidianos enfrentados por sua personagem Bia Sabiá. Na Enciclopédia dos Quadrinhos, 2011, o verbete de Ciça fala de sua carreira, personagens e afirma que Bia Sabiá era feita "especialmente para publicações femininas" (Goida e Kleinerd, 2011: 95). A personagem era figura recorrente nos três jornais alternativos feministas citados neste artigo. A curadoria dos organizadores de tais coletâneas, portanto, atinge a produção de mulheres em dois níveis. Primeiro na negação absoluta do trabalho das mulheres, ao criar vastas listas com total ausência de quadrinistas de humor e cartunistas. Segundo no filtro que seleciona o que é publicado ou não, quando mulheres tem sua obra reconhecida. Trata-se de uma dupla negação do "feminino".

A obra que é alvo de análise na sequência, que promete contar uma história do Brasil através da caricatura, é exemplo perfeito dessa separação público e privado. 
Além do livro não contar com uma única autora mulher, as mulheres quase não são representadas e quando são merecem o pano de fundo. Outro elemento que merece destaque é a questão do regionalismo.

As autoras citadas em antologias e coletâneas integram o eixo Rio-São Paulo. Bebel, ilustradora e cartunista gaúcha (Fonseca, 1999: 277), não é citada em nenhuma das obras analisadas, muito provavelmente por seu lugar de atuação ser o Rio Grande do Sul, estado em que é figura bastante conhecida. Essa é uma crítica que pode ser estendida aos jornais feministas explorados como fonte secundária. No entanto, como a maioria das autoras publicadas nesses jornais não são citadas em coletâneas, antologias e enciclopédias, é difícil fazer uma reflexão mais detida a esse respeito. Conceição Cahú era natural de Pernambuco e teve três trabalhos publicados no Brasil Mulher e dois publicados no Nós Mulheres, ela não é citada em nenhuma das coletâneas analisadas, nem nas da segunda metade do século XX, nem nas do começo do século XXI. Focada mais na questão da crítica social do que no humor, Cahú é citada por Amelinha Teles e Rosalina Leite por fazer charges e cartuns que problematizavam as mulheres trabalhadoras (2013: 64). Inclusive, foi ela a responsável por apresentar a coluna de humor que estreou no jornal Nós Mulheres em marçoabril de 1977. A coluna intitulada O humor de Nós Mulheres foi inaugurada com um breve relato de Hilde Weber, outra autora ignorada por todas as coletâneas citadas neste artigo. No texto fundante da coluna, Cahú afirmou:

O nosso objetivo é criar uma página de humor dentro do nosso jornal, contínua, e, obviamente, alegre embora nem sempre o humor seja alegre. Os cartunistas brasileiros são excelente (sic), mas devido ao mercado estreito e solapado pelo similar extrangeiro (sic), em concorrência francamente desleal ("cobra preço de banana”) não tem tido muitas oportunidades de explorar seu potencial, fundamental na criação de uma cultura num país como este nosso; daí que, quantos mais páginas, revistas, livros de humor brasileiro, do povo brasileiro, melhor. Bom, dentre os conhecidos humoristas brasileiros, existem mulherescujotrabalho de alto nível, colecionamos para iniciar esta série. Comecemos com Wilde Weber (sic), que nos contará sua experiência, já que pioneira (Cahu, 1976: 9).

Cahú apresenta a coluna falando da importância da valorização do produto nacional e, mesmo sem afirmar, dá início a esse projeto de humor do jornal com uma cartunista mulher. Fonseca aponta que Hilde Weber começou ilustrando textos literários, noticiário político e matérias esportivas nas publicações de $A$ Noite. Nos anos 1930 trabalhou para os Diários Associados, publicando principalmente no $O$ Cruzeiro. Entre 1950 e 1962 foi cartunista da Tribuna da Imprensa. Colaborou ainda com o Estado de São Paulo e a revista Visão, com foco na caricatura política (Fonseca, 1999: 251). A cartunista também é indicada como uma das pioneiras do desenho, da 
ilustração e dos quadrinhos no Brasil (Crau [et al], 2014: 68). Apesar desse currículo, Hilde Weber não foi citada por nenhuma das obras analisadas.

As obras citadas para colaborar na reflexão sobre o humor gráfico das mulheres na segunda metade do século XX indicam um cenário desolador. Mesmo sendo um número reduzido, elas são sintomáticas do lugar reservado às mulheres no período. Dez em humor, de 1968, não citou uma única autora. Podemos ponderar que a obra não era ambiciosa e reuniu apenas dez cartunistas. Aceitando esse argumento, podemos então observar os números da Antologia brasileira de humor, publicada em dois volumes, em 1976, com mais de 500 páginas. De 84 nomes, apenas dois são de mulheres. No auge da produção de humor gráfico brasileiro, as mulheres não são nem $5 \%$ dos nomes citados. $\mathrm{O}$ fato se agrava quando identificamos que nomes muito conhecidos foram excluídos das coletâneas, a exemplo de Hilde Weber, Cahú, Nair de Teffé e tantas outras que encontraram acolhida, inclusive, na imprensa alternativa feminista do período. Resta-nos, portanto, observar o lugar reservado às mulheres em obras do começo do século XXI.

\section{O passado-presente}

O livro Uma história do Brasil através da caricatura, de Renato Lemos, foi publicado em 2001, reunindo caricaturas, charges e tiras para narrar a história do Brasil de 1840 a 2006. Apesar do objetivo do livro não ser propriamente construir um material de consulta sobre o humor gráfico no Brasil, é importante observar como o autor escolheu contar essa história, isto é, com que imagens e autores. O livro tem um projeto gráfico sofisticado, papel de qualidade, capa dura e imagens impressas em excelente qualidade ao longo de 174 páginas. Reproduz 185 charges/ caricaturas/tiras de 56 chargistas diferentes, todos homens. Não há uma única charge, tira ou caricatura assinada por uma mulher. Na apresentação, Renato Lemos, historiador, afirma que o livro foi pensado para proporcionar prazer: "Prazer de tomar conhecimento do trabalho de alguns dos mais importantes desenhistas brasileiros" (2001: 5). Com tristeza concluímos que as mulheres não apenas não escrevem a história, como também não integram o vasto número de 56 "dos mais importantes desenhistas brasileiros”. Com a obra somos informadas que é possível narrar quase 200 anos de história sem a produção de uma única mulher.

A abordagem não é novidade. De algum modo o autor reproduz um problema da ciência história que pouco esforço tem dedicado a se repensar como tendo sido construída no masculino. Como campo científico a história já reconhece o apagamento das mulheres na narrativa histórica, daí a emergência de áreas como a história das mulheres e dos estudos de gênero. Em termos de transformação do próprio campo, no entanto, esse reconhecimento não gerou mudanças na forma de fazer história. Além disso, é relevante destacar que não se trata de incluir algumas páginas novas na história, isto é, não bastaria a Renato Lemos incluir algumas autoras mulheres na 
sua coletânea, ou mesmo ampliar um pouco mais sua representação, seria necessário refletir sobre a própria constituição do livro que foi concebido no masculino, ao privilegiar uma história política que tem uma noção reduzida de política.

Bonnie Smith aponta como a história moderna ocidental foi atravessada pelo gênero, sendo o trauma uma categoria histórica que se aplica apenas aos homens brancos - experiências de guerra, solução final, etc - as experiências de mulheres, marcadas pela violência naturalizada, pelo estupro e por partos dolorosos, não cabem a uma narrativa profissional e científica (Smith, 2003: 90). Na constituição da história como ciência, portanto, ocorreu a negação do "feminino" e tudo que ele representava. Avançamos em direção ao século XXI, mas pouco mudou na ciência histórica, e menos ainda no humor gráfico.

O livro Entre sem Bater!: O humor na Imprensa: do Barão de Itararéao Pasquim21, de Luis Pimentel, foi publicado em 2004, e realizou uma síntese importante, mas novamente as mulheres são praticamente ignoradas. A capa é composta por uma montagem com 10 capas de publicações como O Cruzeiro, PifPaf, Bundas, O Malho. Das 10 capas, seis tem ou figuras de mulheres ou de partes do corpo de mulheres. Um total de três bundas figuram na capa. A capa, portanto, não faz grandes promessas a uma pesquisa que visa debater o lugar das mulheres no humor gráfico do Brasil.

Em seu capítulo inicial o autor afirma que o Brasil tem os maiores cartunistas, chargistas e quadrinistas e avisa: não é historiador, seu livro é uma declaração de amor e humor a grandes nomes (2004: 10-11). Pimentel fez uma espécie de reportagem que começa no século XIX e se estende até o século XXI, trajeto no qual ele cita inúmeros nomes importantes do humor gráfico no Brasil, o último capítulo é intitulado: "Um time da pesada: outros grandes nomes do humor (nacional) de imprensa", com um adendo “(com o pedido antecipado de perdão por eventual esquecimento)" (2004: 71). No capítulo encontramos uma lista em ordem alfabética de 93 nomes, acompanhados de uma breve biografia profissional. Nomes como Angeli, Henfil, Allan Sieber, Jaguar e Jô Soares são classificados. Sua declaração de amor e humor, infelizmente, não foi dedicada às mulheres. No "time da pesada" estão 92 homens e uma mulher. Parece que o autor é homem de uma mulher só. De fato, o autor precisa de perdão por eventual esquecimento. Sem reflexões ou previsões sobre o significado político de esquecer ou ignorar grandes nomes de mulheres do humor na imprensa, o autor contribui para a construção de um discurso que silencia o humor das mulheres. A única cartunista citada por Pimentel é Nair de Teffé e seu verbete está condicionado a sua condição de filha e esposa.

Filha de um herói da Guerra do Paraguai, o Barão de Teffé, Nair foi educada na França, de onde retornou na adolescência para morar em Petrópolis (RJ) [...] foi a primeira caricaturista mulher a publicar no Brasil, revelando-se nos primeiros anos do século passado. Em 1913 Nair tornou-se primeira dama da república, ao casar-se com o então presidente Marechal Hermes da Fonseca. Ficou viúva dez anos depois, quando para se sustentar colaborou 
com diversas publicações das décadas de 1920 e 1930. No final da vida foi morar em Niterói, sozinha, onde morreu em 1981, aos 95 anos (Pimentel, 2004: 102-103).

Nair de Teffé, apesar de cartunista, tem sua trajetória lembrada a partir de marcadores de gênero que não tem relação com sua vida profissional. $\mathrm{O}$ curto texto a identifica como filha, esposa e viúva. Podemos ponderar que, sendo de família abastada e tendo casado com um presidente, a caricaturista que assinava como Rian, chama a atenção por outros motivos, mas a frase final é reveladora. Nair de Teffé não morreu em Niterói em 1981, aos 95 anos. Ela morreu "sozinha". Nenhum outro nome tem descrição semelhante, os verbetes ou descrevem o traço dos cartunistas ou fazem um breve histórico de carreiras profissionais ${ }^{18}$.

Joaquim da Fonseca, em obra que procura contar a história da imagem gráfica do humor, sem a pretensão de ser uma coletânea ou antologia - por isso não foi selecionado como fonte de análise em si - apresenta Rian a partir de seus vínculos familiares e afetivos. Informa que ela era filha de um barão e que se casou com um presidente e que "Com certeza, foi a primeira caricaturista brasileira do sexo feminino" (Fonseca, 1999: 231). O autor dedica um bom número de linhas à carreira profissional da ilustre caricaturista informando que ela publicou em revistas como Fon-Fon!, O Cinematógrafo, Careta, O Malho, Revista da Semana e na Gazeta de Notícias. Fonseca, contudo, não se contentou com tal descrição, precisou falar de outras qualidades de Nair de Teffé.

Vinda de uma família tradicional e abastada, era uma mulher de extrema beleza pessoal e intensa atividade social [...] Casou em 1913, com o Marechal Hermes da Fonseca, Presidente da República que, apesar de ter enviuvado havia poucos meses, não conseguiu resistir aos seus encantos (Fonseca, 1999: 232).

Rian não teve apenas seu talento reconhecido, como também sua extrema beleza, tão arrebatadora que conquistou até um homem recém-viúvo. Na sequência o autor narra como um belo vestido marfim com uma faixa azul, usado por ela em um baile no Palácio do Itamaraty, teria motivado a mudança da cor da esquadra brasileira que, no dia seguinte após sua aparição, teria adotado as cores do vestido (Fonseca, 1999: 232). Fonseca, contudo, informa que Nair de Teffé morreu em 1981, sem adjetivos qualificantes.

Michelle Perrot aponta como a educação foi, por longo período, negada às mulheres: "Ao longo do século XIX, reitera-se a afirmação de que a instrução é contrária tanto ao papel das mulheres quanto a sua natureza: feminilidade e saber se excluem. A leitura abre as portas perigosas do imaginário. Uma mulher culta não é uma mulher" (Perrot, 2007: 93). Fonseca parece não aceitar que Rian era apenas

18 Vale pontuar que Henfil tem detalhes de sua vida pessoal revelados em função do tom trágico de sua morte e de seu irmão Bentinho. 
talentosa, foi necessário informar que era talentosa e cheia de encantos, uma espécie de necessidade primitiva de aliar seu talento com sua feminilidade. Ao informar sobre outras duas mulheres atuantes no humor gráfico, Hilde Weber e Bebel, o autor não enfatiza tais nuances.

Famílias ricas sabiam da importância de educar as meninas, não a ponto de elas tornarem-se independentes, mas para garantir um bom casamento e uma boa condição social. Em pensionatos as meninas aprendiam sobre as artes do entretenimento (Perrot, 2007: 94). Apesar de mudanças que acompanharam a virada para o século XX, exatamente o período de atuação de Rian, a vida de mulheres artistas não era simples. Fonseca aponta que a caricaturista tinha pensamento bastante avançado para a época. Sua formação incluía cursos na França, tendo estudado, inclusive, modelo vivo (Fonseca, 1999: 231-232). Contudo, a vida das mulheres artistas era difícil. O elogio máximo para o trabalho de uma mulher pintora era, e talvez ainda seja, "[...] é tão boa que parece pintada por um homem” (Perrot, 2007: 102). Se pensarmos que, ainda hoje, o grupo de ativistas-artistas Guerrilla Girls pergunta se as mulheres precisam estar nuas para entrarem em museus, concluímos que as conquistas de Rian são, de fato, invejáveis.

O livro Enciclopédia dos Quadrinhos, de Goida e Andre Kleinert, foi publicado em 2011 e foi uma proposta ambiciosa. Com 525 páginas a coletânea reúne nomes dos quadrinhos do todo o mundo, de A a Z: Brasil, Argentina, Coréia do Sul, Irã, países da Europa, Estados Unidos e etc. Na imensidão da enciclopédia são citadas 27 mulheres. Antes da celebração, contudo, precisamos considerar que apenas a letra A reúne 72 nomes. Em um alfabeto com 26 letras as mulheres não são nem 50\% de uma letra. Em um universo de mais de 500 páginas, através de uma média, concluímos que as mulheres ocuparam em torno de 15 páginas do livro. As brasileiras lembradas são um total de 9: Ciça, Chiquinha, Mariza, Erica Awano, Dadi, Edna Lopes, Maria Aparecida de Godoy, Adriana Melo e Pagu. No verbete de Pagu, os autores informam:

No único número da revista de HQs Manga (PressEditorial, sem data), além de histórias ilustradas por Alain Voss, Marcatti, Jaz, Luiz Gustavo e Péricles (Amigo da Onça), havia uma curiosidade marcante. Os editores encontraram cinco tiras desenhadas por Pagu (Patrícia Rehder Galvão) para o jornal Homem do Povo [...] Jornalista, escritora e ativista, Pagu (que foi a segunda mulher de Osvald de Andrade) deixou para a história das HQs brasileiras essa manifestação gráfica rara (Goidanich e Kleinert, 2011: 367368).

A presença de Pagu em obra que inclui nomes como Trina Robbins, Ciça e Maitena é marcada pela curiosidade. Sua inserção fica entre duas possibilidades: "manifestação gráfica rara" ou "mulher de Osvald de Andrade"? O fato é que seu nome entra a título de exceção em detrimento de nomes como Nair de Teffé, lembrada pela coletânea anterior e esquecida por essa. A impressão geral sobre as poucas mulheres 
listadas é que elas ali se encontram porque fizeram bastante sucesso no Brasil ou no mundo, como é o caso de Alison Bechdel, Marjane Satrape, Claire Bretecher, ou porque são elemento exótico, o que seria o caso de Pagu. Na revista As Periquitas, entretanto, Pagu não é tratada como caso raro e é apontada como a primeira mulher a publicar quadrinhos no Brasil (Crau [et al], 2014: 68). As cartunistas, chargistas e quadrinistas que publicaram nos jornais da imprensa alternativa feminista entre os anos 1970 e 1980, são ignoradas em sua maioria. Célia, Sandra, Cahú e Lilita, por exemplo, não são citadas.

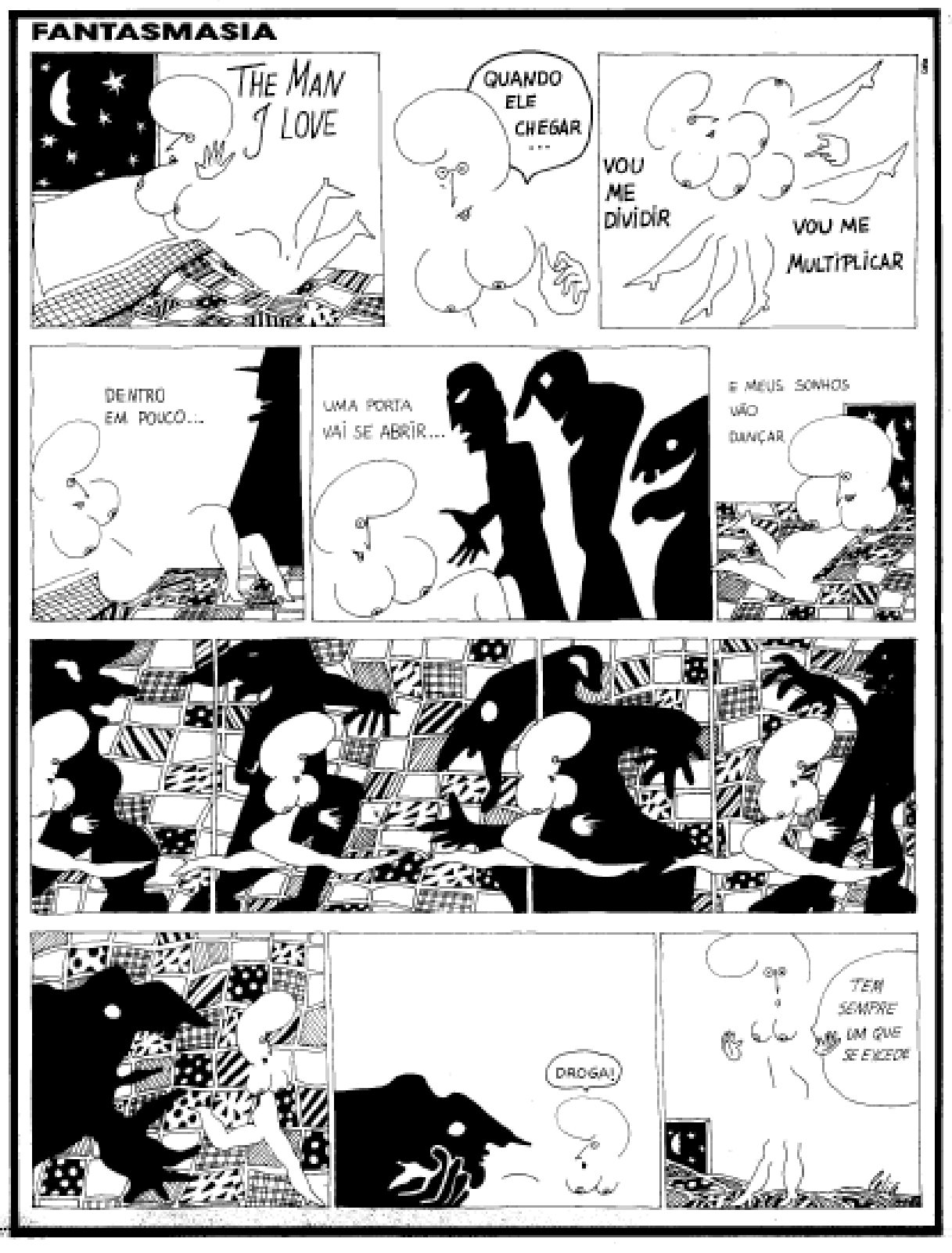

Figura 3 - CÉLIA. (1987). Mulherio. São Paulo. Número 30, Julho, p. 24.

Sendo a obra mais ambiciosa das analisadas, a Enciclopédia dos Quadrinhos, de Goida e Andre Kleinert, encerra um ciclo de silêncios do humor - no início do século XXI - iniciado pela História do Brasil através da caricatura, de Renato Lemos, 
e do Entre sem bater!, de Luis Pimentel. Ciente que a passagem do tempo não vem acompanhada pelo progresso, a conclusão que, juntas, essas três coletâneas reuniram o número de dez mulheres: nove na Enciclopédia dos Quadrinhos, uma no Entre sem bater! e nenhuma no História do Brasil através da caricatura; é preocupante e sinaliza uma omissão que já não pode ser tolerada. Essa omissão fica evidente quando, por exemplo, lançamos o olhar para a imprensa alternativa feminista que reuniu número significativo de cartunistas e quadrinistas de humor.

O jornal Brasil Mulher, em seus 16 números publicados entre 1975 e 1980, publicou 55 charges/tiras/quadrinhos, destas, cinco são assinadas por Lila, Cahú e Ciça - Ciça, juntamente de Mariza, é a mais citada de todas as seis coletâneas aqui analisadas, elas aparecem em duas delas. Vale lembrar que do número total, 21 não são assinadas; 12 são assinadas por Henfil, Gê e Laerte e as outras 17 tem autoria não identificada. A omissão de Cahú nas coletâneas é bastante significativa, ela foi uma artista e ilustradora bastante conhecida, com livros publicados e uma série de exposições realizadas. O fato de Nair de Teffé ser citada em apenas uma coletânea também merece registro, assim como o apagamento de Hilde Weber.

O jornal Mulherio publicou 38 números em oito anos de circulação, entre 1981 e 1988. No total foram publicadas 103 charges e tiras: 39 assinadas por homens; 26 assinadas por mulheres; 24 não assinadas e 12 com autoria não identificada. Trata-se de um total de 14 autoras, incluída Ciça. Das 14 autoras, é possível que pelo menos dez sejam brasileiras: Eliana Paiva, Ciça, Rosana, Lilita e Lilita Figueiredo (provavelmente a mesma autora), Lilá Galvão (talvez a mesma Lila do Nós Mulheres), Roberta Mele, Ana Maria Marques, Angela, Cristina Burger e Célia. Destas, apenas Ciça é citada. Se as coletâneas oferecem silêncio, os jornais feministas ofereceram resistência.

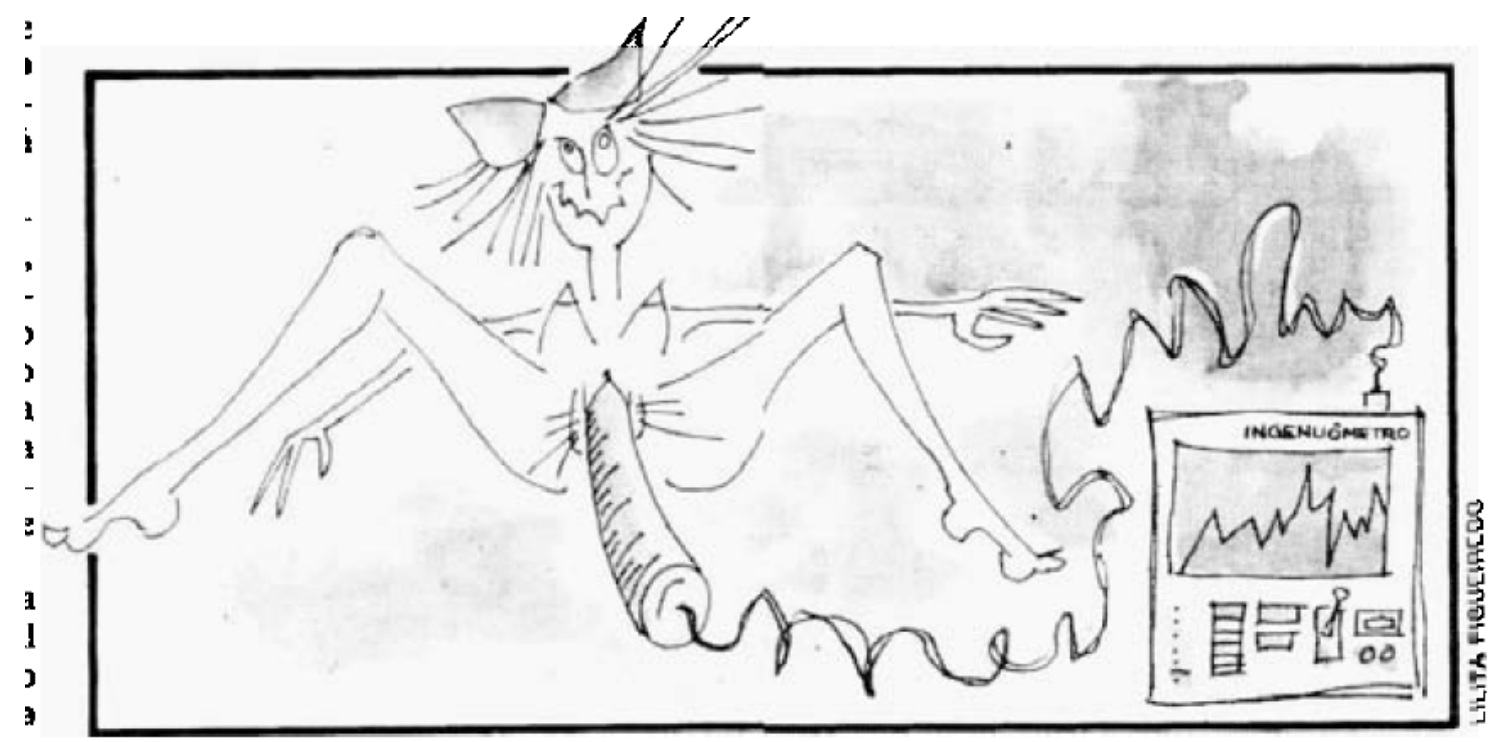

Figura 4 - FIGUEIREDO, Lilita. (1984). Mulherio. São Paulo. Número 19, Novembro-Dezembro, p. 8. 


\section{O presente-futuro ou considerações finais}

A legião de mulheres nos quadrinhos no Brasil é, como a definição da expressão insinua, uma grande unidade de tropas que enfrentam - e protegem - diferentes frentes. Se nas primeiras décadas do século XX as bibliografias apontam informações difusas sobre figuras como Nair de Teffé e Pagu, o cenário para a segunda metade do século XX deveria ser mais promissor. Contudo, a demarcação de poucos nomes, tratados quase como sujeitos singulares, como Hilde Weber, Ciça e Mariza, indicam que a história pouca relação tem com o progresso. Os primeiros anos do século XXI - eis o século das mulheres? - para surpresa de ninguém, conta com publicações grandiosas, mas com números tímidos. A fidelidade de publicações a uma única cartunista, eventualmente duas, e mais eventualmente dez, quando o "primeiro sexo" reúne dezenas, centenas ou milhares de homens, não passa despercebida e é isso que nos mostram as publicações feministas exploradas neste artigo.

Enquanto Dez em Humor, Antologia Brasileira de Humor, Entre sem Bater!, Uma história do Brasil através da caricatura e Enciclopédia dos Quadrinhos mostramnos um cenário de silêncios do humor no Brasil - em teoria um cenário cujo filtro é o talento -, os traços de Lila e Célia nos jornais feministas e das 432 mulheres da lista citada no começo deste artigo, confirmam que o silêncio não combina com as mulheres cartunistas, desenhistas, quadrinistas e ilustradoras. Tais números, para além de questionar os silêncios das obras de humor gráfico, apontam a desobediência de mulheres dispostas a resistir a operações contínuas de silenciamento. Quase 100 anos nos separam de Nair de Teffé e mesmo diante de tanto esforço para garantir modestas cotas às mulheres em coletâneas de humor, a busca por estratégias e alternativas marcou o humor gráfico das mulheres na segunda metade do século XX e começo do século XXI. Se as coletâneas e seus autores demonstram descaso, as mulheres produtoras de humor gráfico no Brasil apontam a disposição para construir caminhos próprios, o que Foucault chamou de contracondutas (Foucault, 2008).

O uso da imprensa alternativa feminista para publicização do humor gráfico de mulheres é comprovação não apenas da existência de mulheres no campo, como da necessidade de debates que superam a discussão sobre política institucional. Com um lápis que riscava as fronteiras entre privado e público, mulheres como Ciça, Lilita, Mariza e outras, demonstravam seu talento e outras formas de produzir humor.

O trabalho quase artesanal dos jornais, especialmente do Brasil Mulher e do Nós Mulheres, é suporte essencial para que hoje possamos observar as obras publicadas na segunda metade do século XX, bem como dos primeiros anos do século XXI, já que a negação das mulheres citadas nestes jornais demonstra que o campo do humor gráfico no Brasil, em termos de publicações, é construído no masculino. Nesse encalço, a Internet emergiu como uma revolução para o trabalho de mulheres no humor gráfico. Se antes havia uma forte dependência de editoras, o que levava à busca por alternativas eficazes, como a publicação em jornais alternativos e nas poucas revistas de quadrinho alternativo do país, hoje a criação de blogs, tumblrs, 
sites e páginas em redes sociais dão visibilidade ao grande número de mulheres atuantes no campo.

O humor gráfico produzido por mulheres no Brasil, nos últimos 100 anos, demonstra a necessidade de uma revisão teórica, histórica e bibliográfica construída a partir da desobediência de cânones e hierarquias de gênero. Listas como a de Aline Lemos, A legião de mulheres nos quadrinhos no Brasil, de 2016, e a revista As Piriquitas, Meninas com humor e opinião, de 2014, evidenciam uma necessidade de renovação que não pode ser silenciada. A defesa da existência de um humor brasileiro, protagonizado por papagaios sempre machos, insinua seus limites há décadas. A fidelidade de coletâneas a uma mulher só - eventualmente a algumas, uma celebração de um amor livre defendido por muitos homens - é uma negação da história das mulheres no humor gráfico do Brasil.

\section{Referências}

\section{Fontes (coletâneas)}

ADAIL [et al]. (1976). Antologia Brasileira de humor (Vol. 1). Porto Alegre: L\&PM.

ADAIL [et al]. (1976). Antologia Brasileira de humor (Vol. 2). Porto Alegre: L\&PM.

GOIDANICH, Hiron Cardoso e KLEINERT, André. (2011). Enciclopédia dos Quadrinhos. Porto Alegre, RS: L\&PM.

JAGUAR [et al]. (1968). Dez em humor. Rio de Janeiro: Editora Expressão e Cultura.

LEMOS, Renato. (2001). Uma história do Brasil através da caricatura. Rio de Janeiro: Bom Texto Editora.

PIMENTEL, Luis. (2004). Entre sem Bater!: O humor na Imprensa: do Barão de Itararé ao Pasquim21. Rio de Janeiro: Ediouro.

\section{Fontes (periódicos)}

Brasil Mulher. São Paulo. Número 11, março de 1978.

Mulherio. São Paulo. Número 19, Novembro-Dezembro de 1984.

Mulherio. São Paulo. Número 3o, Julho de 1987. 
Nós Mulheres. São Paulo. Número 4, Março-Abril de 1977.

\section{Bibliografias}

BEAUVOIR, Simone. (2009). O segundo sexo. Rio de Janeiro: Nova Fronteira.

BARRECA, Regina. (1991). They used to call me snow white... but I drifted. Women's strategie use of humor. Penguin Book's: USA.

CIRNE, Moacy. (1990). História e crítica dos quadrinhos brasileiros. Rio de Janeiro: Ed. Europa.

CRAU [et al]. (2014) As Periquitas. São Paulo: Editora Kalaco.

CRESCÊNCIO, Cintia Lima. (2016). Quem ri por último, ri melhor: humor gráfico feminista (Cone Sul, 1075-1988). Tese (Doutorado em História Cultural) - Programa de Pós-Graduação em História da Universidade Federal de Santa Catarina. Digital.

EUGÊNIO, Jessica Daminelli. (2017). Elas fazem HQ! Mulheres brasileiras no campo das histórias em quadrinhos brasileiras. Dissertação (Mestrado em Sociologia Política) - Programa de Pós-Graduação em Sociologia Política da Universidade Federal de Santa Catarina. Digital.

FONSECA, Joaquim da. (1999). Caricatura: a imagem gráfica do humor. Porto Alegre: Artes e Ofícios.

FOUCAULT, Michel. (2008). Segurança, Território e População. São Paulo: Martins Fontes.

GOODWIN, Ricky. (2011). "A monovisão dos estereótipos no desenho de humor contemporâneo". In: LUSTOSA, Isabel (org). Imprensa, Humor e Caricatura: a questão dos estereótipos culturais. Belo Horizonte: Editora UFMG. p. 535-555.

HENFIL. (2014). Depoimento a Tárik de Souza. Como se faz humor político. São Paulo: Kuarup.

JUNIOR, Gonçalo. (2004). A Guerra dos Gibis: A formação do mercado editorial brasileiro e a censura aos quadrinhos (1933-1964). São Paulo: Companhia das Letras.

OLIVEIRA, Selma Regina Nunes. (2007). Mulher ao Quadrado. As representações femininas nos quadrinhos norte-americanos: permanências e ressonâncias (18951990). Editora Universidade de Brasília: Finatec. 
PERROT, Michelle. (2005). As Mulheres ou os Silêncios da História. Bauru, SP: EDUSC. PERROT, Michelle. (2007). Minha História das Mulheres. São Paulo: Contexto. POSSENTI, Sírio. (2014). Humor, língua e discurso. São Paulo: Contexto.

SILVA, Alba Valédia Tinoco Alves. (2015). Deus e o diabo no humor das mulheres: contos, casos e crônicas com humor escritos por mulheres. Salvador: EDUFBA.

SOIHET, Raquel. (2005). "Zombaria como arma anti-feminista: instrumento conservador entre libertários". Revista Estudos Feministas, vol. 13, n. 3: p. 591-611, setembro-dezembro.

TELES, Amelinha e LEITE, Rosalina Santa Cruz. (2013). Da Guerrilha à Imprensa Feminista. A construção do Feminismo pós-luta armada no Brasil (1975-1980). São Paulo: Intermeios.

VARIKAS, Eleni. (1996). "O pessoal é político: desventuras de uma promessa subversiva”. Tempo, Rio de Janeiro, vol. 2, no 3: p. 59-8o, s/m.

SMITH, Bonnie G. (2003). Gênero e História: homens, mulheres e a prática histórica. São Paulo: EDUSC.

Recebido: 06.08.2018

Aceito: $17 \cdot 10.2018$ 